\title{
A COMPARATIVE STUDY OF SITE OF INFARCTION COMPLICATIONS AND MORTALITY OF PATIENTS SUFFERING FROM ISCHAEMIC HEART DISEASE WITH OR WITHOUT DIABETES
}

\author{
Deepak Kumar1, John Masih², Khileshwar Singh³, Vimal Chandra Bhagat", Chandrakant Diwan', Sanjay Mandavi', Menka Khare ${ }^{7}$, \\ Avon Dhruw 8
}

${ }^{1}$ Assistant Professor, Department of Medicine, Late Baliram Kashyap Memorial Government Medical College, Jagdalpur, Chhattisgarh, India.

${ }^{2}$ Associate Professor, Department of Medicine, Late Baliram Kashyap Memorial Government Medical College, Jagdalpur, Chhattisgarh, India.

${ }^{3}$ Associate Professor, Department of Medicine, Late Baliram Kashyap Memorial Government Medical College, Jagdalpur, Chhattisgarh, India.

${ }^{4}$ Assistant Professor, Department of Medicine, LAMGMC, Raigarh, Chhattisgarh, India.

${ }^{5}$ Assistant Professor, Department of Obstetrics and Gynaecology, JLNMMC, Raipur, Chhattisgarh, India.

${ }^{6}$ Assistant Professor, Department of Medicine, Late Baliram Kashyap Memorial Government Medical College, Jagdalpur, Chhattisgarh, India.

${ }^{7}$ Assistant Professor, Department of Medicine, Late Baliram Kashyap Memorial Government Medical College, Jagdalpur, Chhattisgarh, India.

${ }^{8}$ Medical Officer, Department of Medicine, JLNMMC, Raipur, Chhattisgarh, India.

\section{BACKGROUND}

ABSTRACT

Coronary artery disease accounts for $75 \%$ deaths in diabetics and is characterised by younger age of onset of more advanced disease with multiple vessel involvement and increased frequency, particularly in females. Although, mainly manifested as Angina Pectoris, Myocardial Infarction, Congestive Cardiac Failure and Arrhythmias, it may notoriously be atypical and asymptomatic and contribute to sudden death.

\section{MATERIALS AND METHODS}

A total of one hundred cases of myocardial ischaemia and infarction (50 of IHD with diabetes and another 50 IHD without diabetes) were included in the study. To know the site of infarction, an Electrocardiogram (ECG) was recorded using the Philips 100-page writer machine, which records all the twelve lead and a long rhythm strip at a time. A single observer recorded all the ECG. Reading of ECG was done under various heads.

\section{RESULTS}

On analysis of collected data it has been revealed that $68 \%$ cases had anterior wall lesion, $14 \%$ had inferior wall lesion and the rest $18 \%$ had combination variety amongst the IHD with diabetes cases. Similarly, amongst non-diabetic IHD, 32\% had anterior wall, $24 \%$ had inferior wall and rest $44 \%$ had combination variety. Regarding combination, $30.00 \%$ and $14.00 \%$ cases had a combination of complications in both IHD with diabetes and without diabetes respectively.

\section{CONCLUSION}

It has been revealed that IHD with Diabetes claims more lives than its counterparts IHD with non-diabetes.

\section{KEY WORDS}

Lesions, Arrhythmias, Cardiogenic Shock.

HOW TO CITE THIS ARTICLE: Kumar D, Masih J, Singh K, et al. A comparative study of site of infarction complications and mortality of patients suffering from ischaemic heart disease with or without diabetes. J. Evolution Med. Dent. Sci. 2018;7(33): 3661-3664, DOI: $10.14260 /$ jemds/2018/822

\section{BACKGROUND}

Ischaemic Heart Disease (IHD) has become the most common cardiovascular cause of death and disability. In the highly industrialised countries of the west, it is the dominant cause of death. The incidence of IHD in India is also on the increase

'Financial or Other Competing Interest': None.

Submission 21-03-2018, Peer Review 28-07-2018,

Acceptance 03-08-2018, Published 13-08-2018.

Corresponding Author:

Dr. Deepak Kumar,

Department of Medicine,

Late Baliram Kashyap Memorial Government Medical College,

Jagdalpur, Chhattisgarh, India.

E-mail: drdeepakmdmedicin@gmail.com

DOI: $10.14260 /$ jemds $/ 2018 / 822$

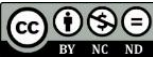

and it is coming to affect the younger age group, lower income group and people in labour class as well as the old and rich. The IHD presents a few peculiarities in the Diabetes Mellitus (DM). It is generally accepted that all age levels DM have increased incidence of IHD. Patients with DM tend to suffer unduly from premature and severe atherosclerosis, Banerjee JC.(1) There is evidence that even when diabetes is first diagnosed, the patient already has an increased tendency to develop coronary artery disease, John $\mathrm{H}$ et al.(2) By taking in account the above facts and as per recommendations of the World Health Organisation (WHO) study group in 1957, that in order to get a comprehensive picture of a disease more and more such studies have to be carried out. Garg Narendra $\mathrm{K}^{(3)}$ and Sharma $A B,(4)$ the authors have undertaken this study with the objective to analyse the Electrocardiography changes (ECG), complications and mortality of the disease. 


\section{MATERIALS AND METHODS \\ Study Design and Setting}

This is a hospital-based case-control study, conducted in the Department of Medicine, Department of Medicine of Pt. J.N.M. Medical College, Raipur (C.G.) and its allied hospital, Dr. Bhim Rao Ambedkar Memorial Hospital, among the patients presenting in OPD and admitted in medicine ward or intensive care unit from the period between May 2003 and May 2004.

\section{Study Subjects}

Total 100 subjects suffering from Ischaemic Heart Disease (IHD) were included in the study $(n=50$, IHD with DM and $\mathrm{n}=50$, IHD without DM). Subjects with Diabetes mellitus were diagnosed as per WHO criteria of diabetes mellitus (fasting blood glucose of $>126 \mathrm{mg} / \mathrm{dL}$ and postprandial $2 \mathrm{hrs}$. blood glucose of $>200 \mathrm{mg} / \mathrm{dL}$ ), selected randomly irrespective of age and sex who gave informed consent were included in the study. Fifty subjects with non-DM were taken as control subjects, were adult and aged more than 30 years.

\section{Study Size and Sampling Procedure}

Following formula was used (Adapted from Kirkwood, 1988)

$\mathrm{n}=(\mathrm{r}+1 / \mathrm{r})\left(\mathrm{p}^{-} \times\left(1-\mathrm{p}^{-}\right)\left(\mathrm{Z}_{\beta}+\mathrm{Z} \alpha / 2\right)^{2} /\left(\mathrm{p}_{1}-\mathrm{p}_{2}\right)^{2}\right.$

$\mathrm{n}=(1+1 / 1)\left(.265 \times(1-.265)(.84+1.96)^{2} /(.33-.10)^{2}=50\right.$

So, Total 50 cases and 50 controls $=100$ subjects

Where: $\mathrm{n}=$ Sample size in the case group

$r=1$ (equal number of cases and controls)

$\mathrm{P}=$ The proportion exposed in the control group is $10 \%$

$\mathrm{Z}_{\beta}=$ For $80 \%$ power $=.84$

$\mathrm{Z} \alpha=$ For 0.05 significance level $=1.96$

\section{Data Collection}

To know the site of infarction an Electrocardiogram (ECG) was recorded using the Philips 100-page writer machine, which records all the twelve lead and a long rhythm strip at a time. A single observer recorded all the ECG.

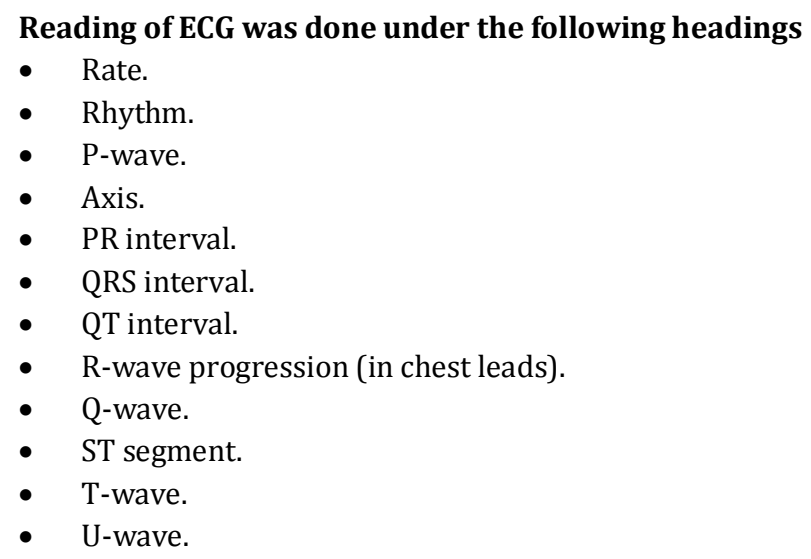

Electrocardiographic manifestations of diagnosis of Myocardial Infarction (MI), Shamroth Leo $(5,6)$

MI results in myocardial necrosis, injury and ischaemia, each of which is reflected by different and distinctive electrocardiographic manifestations. The infarction processes evolve through three easily recognisable electrocardiography phase. These are-

1. The hyperacute phase.

2. The fully evolved phase.

3. The chronic stabilised phase.
1. The Hyperaacute Phase of MI is characterised by four principle Electrocardiography manifestations in leads, which are oriented to the infarction surfaces. These are as follows:

*Increased Ventricular Activation Time (VAT).

*Increased amplitude of R-wave.

*Slope elevation of ST segment.

*Tall and widened T-waves.

2. The fully evolved phase of acute MI is characterised by*The myocardial necrosis is represented by NQS complex.

*The myocardial injury is represented by an elevated and coved and convex upward ST segment.

The myocardial ischaemia is reflected by an inverted, symmetrical T-wave, which is increased in magnitude. The ECG may present with one or more of the following manifestations-

-AQ-wave complex.

-AQR complex.

-A loss of R-wave amplitude.

\section{The chronic stabilised phase:}

Following the fully evolved phase of acute MI, there is a gradual resolution of the abnormalities. The elevated S-T segment gradually returns to baseline, becoming predominantly isoelectric once again. The inverted T-wave gradually regains its positivity. Even the QRS complex may regain some of its previous positivity.

\section{Diagnostic criteria of Myocardial Ischaemia}

The diagnosis of Myocardial Ischaemia depends upon the clinical evaluation of the patient and the ECG changes. The ECG findings are usually limited to the ST segment and Twave abnormalities, Mehta PJ.(7)

\section{These may present in the following two basic forms- \\ *Depression of the ST segment. \\ *Elevation of the ST segment.}

The forms of the ST segment depression considered reflecting to reflect non-transmural myocardial ischaemia.

\section{May take one of the following forms- \\ *Horizontality of the ST segment. \\ *Upward sloping ST segment depression. \\ *Plain ST segment depression. \\ Downward sloping ST segment depression *ST segment depression.}

\section{ST-Segment Elevation}

Reflects transmural myocardial ischaemia. This elevation is spontaneous or exercise induced, may be due to the following conditions-

*Coronary vasospasm.

*Organic stenosis of coronary arteries.

*Left ventricular aneurysm.

*Impaired left ventricular function.

\section{T-Wave Changes}

The T-wave associated with coronary insufficiency has inverted, symmetrical limbs and sharply pointed arrowhead 
vertex or nadir. The associated ST segment usually shows as upward convexity. Sometimes, the T-wave becomes taller as well as pointed and symmetrical. Coronary insufficiency may also be reflected by an increasing QRST angle in both the frontal and horizontal planes, Goldschalager N and Goldman MJ.(8)

\section{Statistical Analysis}

The data analysis was done with the help of IBM SPSS 22 software. Data was expressed as a percentage and mean \pm SD. Student's t-test was used to check the significance of the difference between two parameters in parametric data. Chisquare test was used to analyse the significance of the difference between the frequency distribution of the data. A p-value $<0.05$ was considered as statistically significant.

\section{RESULTS}

There were a significantly higher proportion (68\%) of cases of IHD with Diabetes having anterior wall lesion $\left(p=0.003^{*}\right)$ in comparison to low proportion (32\%) of their counterparts without Diabetes. While in case of inferior wall lesion it is reverse, i.e. significantly more $(24.00 \%)$ belongs to IHD without Diabetes $\left(\mathrm{p}=0.005^{*}\right)$ in comparison to only $14 \%$ cases with Diabetes (Table-I). On further analysis, it has been revealed that only half $(22 \%)$ of the cases belong to IHD with Diabetes with a combination (Ant. + Inf., Inf. + Sept., Inf. + Lat., Inf. + Lat. and RVI + Inf.) of site of infarction in comparison to their counterparts (44.00 \%) IHD without Diabetes (Graph-I to VI).

\section{Complications}

Table-II shows that $22 \%$ patients of IHD with Diabetes in comparison to $26 \%$ IHD without Diabetes met the Lt. ventricular failure, while two percent in each have gone into Cardiogenic shock $\left(p=0.045^{*}\right)$. The table further reveals that there were two percent cases of IHD with Diabetes who showed a conduction defect in comparison to nil without Diabetes. The table also reveals that $30.00 \%$ and $14.00 \%$ cases had a combination of complications in both IHD with Diabetes and without Diabetes respectively ( $p=0.001^{*}$ ).

Table-III reveals that $20 \%$ and $14 \%$ of patients belongs to IHD with Diabetes and without Diabetes respectively were expired $\left(p=0.009^{*}\right)$. It shows that IHD with Diabetes claims more lives than its counterparts non-diabetes; hence, patients suffering from diabetes with IHD must be more serious about the treatment of the disease.

\begin{tabular}{|c|c|c|c|c|c|c|}
\hline \multirow{2}{*}{$\begin{array}{c}\text { Site of } \\
\text { Infarction }\end{array}$} & $\begin{array}{c}\text { IHD with } \\
\text { Diabetes } \\
\text { Cases }\end{array}$ & $\begin{array}{c}\text { IHD without } \\
\text { Diabetes } \\
\text { Cases }\end{array}$ & $\chi^{2}$ & P-value \\
\cline { 2 - 7 } & $\begin{array}{c}\text { No. of } \\
\text { Patient }\end{array}$ & $\%$ & $\begin{array}{c}\text { No. of } \\
\text { Patient }\end{array}$ & $\%$ & & \\
\hline Anterior & 34 & 68 & 16 & 32 & 1.116 & $0.003^{* *}$ \\
\hline Inferior & 07 & 14 & 12 & 24 & 1.646 & $0.005^{* *}$ \\
\hline Posterior & -- & -- & -- & -- & & \\
\hline \multicolumn{7}{|c|}{ Combination } \\
\hline Ant. + Inf. & 02 & 04 & 04 & 08 & 0.604 & 0.126 \\
\hline Inf. + Post & -- & -- & -- & -- & & \\
\hline Inf. + Sept. & 01 & 02 & 02 & 04 & 0.652 & 0.773 \\
\hline Inf. + Lat & 01 & 02 & 04 & 08 & 1.773 & 0.649 \\
\hline RVI + Inf. & 05 & 14 & 12 & 24 & 0.649 & $0.045^{*}$ \\
\hline Total & $\mathbf{5 0}$ & $\mathbf{1 0 0}$ & $\mathbf{5 0}$ & $\mathbf{1 0 0}$ & & \\
\hline Table I. Distribution of Patients as per Site of Infarction \\
\hline
\end{tabular}

Notes: $\chi 2$ test was done to obtain the P-value; ${ }^{*} \mathrm{P}$-value was significant $(\mathrm{p}<0.05)$.

\begin{tabular}{|c|c|c|c|c|c|c|}
\hline \multirow[t]{2}{*}{ Complications } & \multicolumn{2}{|c|}{$\begin{array}{l}\text { IHD with } \\
\text { Diabetes } \\
\text { Cases }\end{array}$} & \multicolumn{2}{|c|}{$\begin{array}{c}\text { IHD without } \\
\text { Diabetes } \\
\text { Cases }\end{array}$} & \multirow[t]{2}{*}{$\chi^{2}$} & \multirow[t]{2}{*}{$\begin{array}{c}P- \\
\text { value }\end{array}$} \\
\hline & \begin{tabular}{|c|} 
No. of \\
Patient
\end{tabular} & $\%$ & \begin{tabular}{|c|} 
No. of \\
Patient
\end{tabular} & $\%$ & & \\
\hline $\begin{array}{l}\text { Lt. Ventricular } \\
\text { failure }\end{array}$ & 11 & 22 & 30 & 26 & 0.791 & $0.006^{*}$ \\
\hline $\begin{array}{l}\text { Cardiogenic } \\
\text { shock }\end{array}$ & 01 & 02 & 01 & 02 & 3.778 & 0.638 \\
\hline RV Infarction & -- & -- & -- & -- & & \\
\hline Arrhythmias & -- & -- & -- & -- & & \\
\hline $\begin{array}{c}\text { Conduction } \\
\text { defect }\end{array}$ & 01 & 02 & -- & -- & & \\
\hline $\begin{array}{c}\text { Combination } \\
\text { (LVF + Arrhy., } \\
\text { LVF + } \\
\text { Cardiogenic } \\
\text { shock) }\end{array}$ & 15 & 30 & 07 & 14 & 0.400 & $0.001^{*}$ \\
\hline
\end{tabular}

Notes: $\chi 2$ test was done to obtain the p-value; ${ }^{*}$-value was significant $(\mathrm{p}<0.05)$.

\begin{tabular}{|c|c|c|c|c|}
\hline & $\begin{array}{c}\text { No. of } \\
\text { Patient }\end{array}$ & $\begin{array}{c}\text { No. of Cases } \\
\text { Expired }\end{array}$ & $\boldsymbol{\chi}^{\mathbf{2}}$ & P-value \\
\hline & $\mathbf{n}$ & $\mathbf{N}(\mathbf{n} \%)$ & & \\
\hline Diabetics & 50 & $10(20.00)$ & 1.208 & $0.009^{*}$ \\
\hline $\begin{array}{c}\text { Non- } \\
\text { Diabetics }\end{array}$ & 50 & $07(14.00)$ & & \\
\hline Total & 100 & $17(34.00)$ & & \\
\hline \multicolumn{7}{|c|}{ Table III. Mortality in Diabetic and Non-Diabetic IHD } \\
Patients
\end{tabular}

Figures in parenthesis indicate percentage.

Notes: $\chi 2$ test was done to obtain the p-value; ${ }^{*} \mathrm{P}$-value was significant $(\mathrm{p}<0.05)$.

\section{DISCUSSION}

Mehta KK(9) reported in his study that out of 25 cases each of IHD with Diabetes 19 cases had anterior wall lesion and the rest 06 cases had inferior wall lesion, while in without diabetes 17 cases had anterior wall lesion and the remaining 08 cases had inferior wall lesion. Thus, there is almost no difference in the site of infarct or ischaemia in cases of IHD in diabetics and non-diabetics. Thus, the findings of the present study are more or less in conformity with the findings of the Mehta KK.(9)

The incidence of death from IHD with DM was $13.9 \%$ in the series of Vaishnava $\mathrm{H}$ et al,(10) while in the present study it was $10.00 \%$ which again is more or less in accordance of the findings of Vaishnava $\mathrm{H}$ et al.(10)

\section{CONCLUSION}

Thus, a great deal of emphasis is to be given for early screening and diagnosis of diabetes, good glycaemic control and modification of coronary risk factors in diabetes by lifestyle improvement and pharmacotherapy to reduce the incidence of IHD, its complications and mortality especially with diabetes.

\section{ACKNOWLEDGEMENT}

The authors are gratefull to Dr. A. K. Bansal, Ex-Professor and H.O.D., Department of Community Medicine, Govt. Medical 
College, Jagdalpur (Bastar), India, for his guidance and encouragement in preparing this manuscript.

\section{REFERENCES}

[1] Banerjee JC. Cardiovascular complications in diabetes mellitus. Ind Heart J 1966;18:219-36.

[2] Herlitz J, Malmberg K, Karlson BW, et al. Mortality \& morbidity during a five year follow up of diabetics with myocardial infarction. Act Med Scand 1988;224(1):31-8.

[3] Narendra GK. Evaluation of the impact of emesis and emesis plus purgation therapy. Research J Pharmacology and Pharmacodynamics 2010;2(2):201-2.

[4] Narendra GK, Sharma AB. Epidemiological profile of patients attending a tertiary care hospital, Muktsar, Punjab, India. Research J Pharmacology and Pharmacodynamics 2011;3(6):311-7.
[5] Leo S. Coronary insufficiency: an introduction to electrocardiography. $7^{\text {th }}$ edn. Blackwell Science 1990: p. 75-188.

[6] Leo S. Myocardial Infarction: an introduction to electrocardiography. $7^{\text {th }}$ edn. Blackwell Science 1990: p. 131-55.

[7] Mehta's PJ. Understanding Electrocardigraphy (ECG). $6^{\text {th }}$ edn. The National Book depot, opp. Wadia Children Hospital, Parel, Mumbai-400012. 2002.

[8] Goldschalager N, Goldman MJ. Normal electrocardiogram: principles of clinical electrocardiography. $13^{\text {th }}$ edn. Appleton \& Lange 1989: p. 23-38.

[9] Mehta KK. Comparative study of IHD in diabetics and non-diabetics ischaemic heart disease in diabetes. JAPI 1976;18:261-7.

[10] Vaishnava H, Dixit NS, Soloman SK. A study in retrospect of hospitalized patients of diabetes mellitus in South India. JAPI 1964;12:255-76. 